\title{
Profiling of Biomarkers for the Exposure of Polycyclic Aromatic Hydrocarbons: Lamin-A/C Isoform 3, Poly[ADP-ribose] Polymerase 1, and Mitochondria Copy Number Are Identified as Universal Biomarkers
}

\author{
Hwan-Young Kim,, ${ }^{1,2}$ Hye-Ran Kim,, ${ }^{2,3}$ Min-Gu Kang, ${ }^{1}$ Nguyen Thi Dai Trang, ${ }^{2}$ \\ Hee-Jo Baek, ${ }^{4}$ Jae-Dong Moon, ${ }^{4}$ Jong-Hee Shin, ${ }^{1}$ Soon-Pal Suh, ${ }^{1}$ Dong-Wook Ryang, \\ Hoon Kook, ${ }^{4}$ and Myung-Geun Shin ${ }^{1,2,4}$ \\ ${ }^{1}$ Department of Laboratory Medicine, Chonnam National University Medical School and Chonnam National University \\ Hwasun Hospital, 160 Ilsimri, Hwasun-eup, Hwasun-gun, Jeollanam-do 519-809, Republic of Korea \\ ${ }^{2}$ Brain Korea 21 Plus Project, Chonnam National University Medical School, Gwangju, Republic of Korea \\ ${ }^{3}$ Laboratory of Metabolism, National Cancer Institute, National Institutes of Health, Bethesda, MD, USA \\ ${ }^{4}$ Environment Health Center for Childhood Leukemia and Cancer, Chonnam National University Hwasun Hospital, \\ Hwasun, Republic of Korea \\ Correspondence should be addressed to Myung-Geun Shin; mgshin@chonnam.ac.kr
}

Received 28 February 2014; Revised 2 June 2014; Accepted 4 June 2014; Published 10 July 2014

Academic Editor: Giulio Mengozzi

Copyright (C) 2014 Hwan-Young Kim et al. This is an open access article distributed under the Creative Commons Attribution License, which permits unrestricted use, distribution, and reproduction in any medium, provided the original work is properly cited.

\begin{abstract}
This study investigated the profiling of polycyclic aromatic hydrocarbon- (PAH-) induced genotoxicity in cell lines and zebrafish. Each type of cells displayed different proportionality of apoptosis. Mitochondrial DNA (mtDNA) copy number was dramatically elevated after 5-day treatment of fluoranthene and pyrene. The notable deregulated proteins for PAHs exposure were displayed as follows: lamin-A/C isoform 3 and annexin A1 for benzopyrene; lamin-A/C isoform 3 and DNA topoisomerase 2-alpha for pentacene; poly[ADP-ribose] polymerase 1 (PARP-1) for fluoranthene; and talin-1 and DNA topoisomerase 2-alpha for pyrene. Among them, lamin-A/C isoform 3 and PARP-1 were further confirmed using mRNA and protein expression study. Obvious morphological abnormalities including curved backbone and cardiomegaly in zebrafish were observed in the 54 hpf with more than $400 \mathrm{nM}$ of benzopyrene. In conclusion, the change of mitochondrial genome (increased mtDNA copy number) was closely associated with PAH exposure in cell lines and mesenchymal stem cells. Lamin-A/C isoform 3, talin-1, and annexin A1 were identified as universal biomarkers for PAHs exposure. Zebrafish, specifically at embryo stage, showed suitable in vivo model for monitoring PAHs exposure to hematopoietic tissue and other organs.
\end{abstract}

\section{Introduction}

Polycyclic aromatic hydrocarbons (PAHs) are ubiquitous environmental toxicants found in air, water, plants, and soils which are present as volatile, semivolatile, and particulate pollutants [1]. PAHs have been of increasing concern in the human health field due to their wide-spread dispersion in the environment and the adverse health effects associated with PAHs exposure such as carcinogenesis and endocrine disruption. Although the adverse effects of individual PAHs are not exactly alike, the United States Environmental Protection Agency (EPA) has designated 32 PAHs compounds as priority pollutants (http://www.epa.gov/). The toxicity of PAHs is structure dependent. Benzopyrene (BaP) among $32 \mathrm{PAH}$ compounds is notable for being the first chemical carcinogen to be discovered $[2,3]$. 
The most commonly used biomarkers of PAHs exposure are metabolites of PAHs, particularly 1-hydroxypyrene (1$\mathrm{OHP}$ ), and PAH-DNA or protein adducts [3]. 1-OHP is the principal product of pyrene metabolism, representing $90 \%$ of its metabolites [4]. Following inhalation, the half-life of $1-\mathrm{OHP}$ is on average about $18-20$ hours [5-7]. Pyrene is the only known precursor of 1-OHP [8]; it forms a consistent proportion of higher molecular weight PAHs in the environment [9]. Main analytical methods employed to measure 1-OHP are high performance liquid chromatography (LC) combined with fluorescence detection and gas chromatography with mass spectrometry $[10,11]$.

Biomarkers to assess exposure to PAHs at high levels are well studied, but more work is needed to validate these biomarkers when exposure occurs at low, environmental levels. Most reported biomarkers for PAHs exposure were mainly targeted against nuclear genome and proteome as well as metabolites in either serum or urine. Moreover, biomarkers as mentioned in several studies [3] did not reflect PAHs exposure sensitively in genomic and proteomic level.

Enormous strides have recently been made in our understanding of the biology and pathobiology of mitochondria. Many diseases have been identified as caused by mitochondrial dysfunction, and many pharmaceuticals have been identified as previously unrecognized mitochondrial toxicants. A much smaller but growing reports indicate that mitochondria are also targeted by environmental pollutants [12]. Past evidence had indicated that the mtDNA repair capacity is limited and that the proximity of mtDNA to sites of reactive oxygen species generation suggested that mtDNA may be more susceptible to mutation than nuclear DNA. Our laboratory has recently reported that hnRNP protein and the change of mitochondrial genome are recognized as novel and useful markers for benzene exposure [13]. Moreover, there is currently a paucity of data on the direct effects of PAHs in primary hematopoietic cells and various cell lines.

In zebrafish, hundreds of genes involved in the formation of virtually every organ system have been identified by largescale mutagenesis screening [14]. Consequently, the phenotypes resulting from loss of gene function through mutation can be compared to malformations resulting from embryonic exposure to contaminants. This "chemical genetic" approach has been used recently to identify specific mechanisms of developmental toxicity $[15,16]$.

Therefore, this study investigated to identify new biomarkers and pathobiological role for PAHs exposure, especially $\mathrm{BaP}$ using targeted mitochondrial genomic and proteomic approach in cell line, peripheral blood/mesenchymal stem cell, and in vivo zebrafish model.

\section{Materials and Methods}

2.1. Reagents and Cell Lines. Cell lines (K562, THP-1, MOLT4, and HL-60 cells) were obtained from the American Type Culture Collection, which were cultured in RPMI 1640 medium (Gibco Laboratories, Grand Island, NY, USA) supplemented with $10 \%$ fetal bovine serum (Gibco) (see Supplementary Table 1 in Supplementary Material available online at http://dx.doi.org/ 10.1155/2014/605135).
Previous published protocol was used for the isolation and characterization of bone marrow-derived mesenchymal stem cells (h-TERT) [17]. For in vitro cell line study, cells were cultured and maintained in RPMI media containing $10 \%$ fetal bovine serum and four types of PAHs such as BaP, pentacene, fluoranthene, and pyrene were added in the cell culture media with $100 \mu \mathrm{M}$ concentration.

2.2. Chemicals. $\mathrm{BaP}$ (purity $>99 \%$ ), fluoranthene (99\%), pentacene $(>99 \%)$, and pyrene $(>99 \%)$ were purchased from Sigma (Sigma-Aldrich, St. Louis, MO, USA). Stock PAHs solutions were made in dimethyl sulfoxide (DMSO) (SigmaAldrich) at concentration of $100 \mu \mathrm{M}$.

2.3. Cytotoxicity Assay. Cytotoxicity assays were carried out using the Enhanced Cell Viability Assay Kit (EZ-CyTox, Daeil Lab Service Co., Seoul, Korea) protocol. The absorbance (A450) of each well was measured using a VERSA Max microplate reader (Molecular Devices, Sunnyvale, CA, USA).

2.4. Determination of mtDNA Copy Number. mtDNA copy number was determined according to our published protocol [13]. For in vitro model study, the purified PCR product of cytochrome $b$ (Cytb) gene was inserted into pGEM-T easy vector and E. coli JM 109 cells (Promega, Madison, WI, USA) were transformed in order to obtain recombinant plasmids. The mtDNA copy number was calculated using the following formula: $[X \mu \mathrm{g} / \mu \mathrm{L}$ plasmid DNA/4419 (plasmid length) $\times$ $660] \times 6.022 \times 10^{23}=Y$ molecules $/ \mu \mathrm{L}$, where $X$ represents the concentration of plasmid DNA and $Y$ represents copy number. For in vivo model study, a mixture of $25 \mu \mathrm{L}$ containing $12.5 \mu \mathrm{L} 2 \mathrm{x}$ QuantiTect SYBR green PCR master mix (Qiagen, Valencia, CA, USA), $400 \mu \mathrm{M}$ Cytb primers forward (5'-TTCTGAGGGGCCACAGTAAT- $\left.3^{\prime}\right)$ and reverse $\left(5^{\prime}\right.$-GGGGTTATTTGATCCGGTTT- ${ }^{\prime}$ ), and $50 \mathrm{ng}$ of total DNA were used for the PCR with the CFX96 real-time system (Bio-Rad, Hercules, CA, USA). For PCR, $95^{\circ} \mathrm{C}$ for 15 minutes was followed by 35 cycles of 20 seconds at $94^{\circ} \mathrm{C}, 30$ seconds at $52^{\circ} \mathrm{C}, 30$ seconds at $72^{\circ} \mathrm{C}$, and a melting reaction with a decrease of $1^{\circ} \mathrm{C}$ per cycle between $72^{\circ} \mathrm{C}$ and $92^{\circ} \mathrm{C}$.

2.5. Direct Sequencing of mtDNA Control Region. This study used a published protocol to amplify and sequence the mtDNA control region gene and minisatellites (303 poly C, 16189 poly $\mathrm{C}$ and 514 (CA) repeat) [13]. The mtDNA sequences obtained were analyzed using the Revised Cambridge Reference Sequence (http://www.mitomap.org/), Blast2 program (http://www.ncbi.nlm.nih.gov/blast/bl2seq/wblast2.cgi), and the MitoAnalyzer (http://www.cstl.nist.gov/biotech/strbase/mitoanalyzer.html) to identify mtDNA aberrations.

\subsection{Proteomic Assay of Mitochondria-Rich Cellular Fraction}

2.6.1. One-Dimensional SDS-Polyacrylamide Gel Electrophoresis. Briefly, an equal amount of proteins $(30 \mu \mathrm{g})$ was then separated on NuPAGE 4-12\% Bis-Tris Gel (Invitrogen; Carlsbad CA, USA). After separation, the gel was stained with GelCode Blue Stain Reagent (Thermo scientific) and the blue-stained 
gel lanes were removed by manual cutting. Each blue-stained gel lane was separately cut into 5 slices. Each of these gel slices was then further cut into sizes of $\sim 1 \mathrm{~mm}^{3}$ and transferred to a clean $1.5 \mathrm{~mL}$ tube.

2.6.2. Enzymatic In-Gel Digestion. The separated proteins were excised from the gel and the gel pieces containing protein were destained with $50 \%$ acetonitrile (ACN) containing $50 \mathrm{mM} \mathrm{NH}_{4} \mathrm{HCO}_{3}$ and the gel pieces were vortexed until Coomassie Brilliant Blue was completely removed. These gel pieces were then dehydrated in $100 \% \mathrm{ACN}$ and vacuum-dried for 20 min with SpeedVac. For the digestion, gel pieces were reduced using $10 \mathrm{mM}$ dithiothreitol in $50 \mathrm{mM} \mathrm{NH}_{4} \mathrm{HCO}_{3}$ for $45 \mathrm{~min}$ at $56^{\circ} \mathrm{C}$, followed by alkylation of cysteines with $55 \mathrm{mM}$ iodoacetamide in $50 \mathrm{mM} \mathrm{NH}_{4} \mathrm{HCO}_{3}$ for $30 \mathrm{~min}$ in the dark. Finally, each of gel pieces was treated with $12.5 \mathrm{ng} / \mu \mathrm{L}$ sequencing grade modified trypsin (Promega) in $50 \mathrm{mM}$ $\mathrm{NH}_{4} \mathrm{HCO}_{3}$ buffer $(\mathrm{pH} 7.8)$ at $37^{\circ} \mathrm{C}$ overnight. Following digestion, tryptic peptides were extracted with $5 \%$ formic acid in 50\% ACN solution at room temperature for $20 \mathrm{~min}$. The supernatants were collected and dried with SpeedVac. Resuspended samples in $0.1 \%$ formic acid were purified and concentrated using C18 ZipTips (Millipore, Billerica, MA, USA) before mass spectrometry (MS) analysis.

2.6.3. Nano-LC-Electrospray Ionization-MS/MS Analysis. The tryptic peptides were loaded onto a fused silica microcapillary column $(12 \mathrm{~cm} \times 75 \mu \mathrm{m})$ packed with $\mathrm{C} 18$ reversed phase resin $(5 \mu \mathrm{m}, 200 \AA)$. LC separation was conducted under a linear gradient as follows: a $3-40 \%$ solvent B (ACN containing $0.1 \%$ formic acid) gradient (solvent A; DW containing $0.1 \%$ formic acid), with a flow rate of $250 \mathrm{~nL} / \mathrm{min}$, for 60 minutes. The column was directly connected to linear trap quadropole linear ion-trap mass spectrometer (Finnigan, San Jose, CA, USA) equipped with a nanoelectrospray ion source. The electrospray voltage was set at $1.95 \mathrm{kV}$, and the threshold for switching from MS to MS/MS was 500. The normalized collision energy for MS/MS was 35\% of main radio frequency amplitude and the duration of activation was $30 \mathrm{~ms}$. All spectra were acquired in data-dependent scan mode. Each full MS scan was followed by five MS/MS scans corresponding to the range from the most intense to the fifth intense peaks of full MS scan. Repeat count of peak for dynamic exclusion was 1 , and its repeat duration was 30 seconds. The dynamic exclusion duration was set for 180 seconds and the width of exclusion mass was $\pm 1.5 \mathrm{Da}$.

2.6.4. Database Searching and Validation. The acquired LC-electrospray ionization-MS/MS fragment spectra were searched in the BioWorksBrowser (version Rev. 3.3.1 SP1, Thermo Fisher Scientific Inc.) with the SEQUEST search engines against National Center for Biotechnology Information (http://www.ncbi.nlm.nih.gov/) nonredundant human database.

2.7. Quantitative mRNA Expression Study. Total RNA was extracted using the QIAamp RNA Blood Mini kit (Qiagen). Reverse transcription produced cDNAs using Superscript III
(Applied Biosystems). The expression of poly[ADP-ribose] polymerase 1 (PARP-1) and lamin A/C (LMNA) mRNA was quantified using QuantiTect SYBR green PCR master mix (Qiagen), PARP-1 forward: 5'-GAGGAAGTAAAGGAAGCCAA-3', PARP-1 reverse: $5^{\prime}$-CACAACTTCAACAGGCTCT-3', LMNA forward: 5'-AAGCTTCGAGACCTGGAG-3', LMNA reverse: $5^{\prime}$-TCCAAGAGCTTGCGGTA-3', and $\beta$-actin mRNA as a normalization control. The $\Delta \Delta \mathrm{Ct}$ method was used to calculate relative changes in gene expression determined by real-time quantitative PCR using CFX96 (Bio-Rad). Normalization was achieved using Ct values of PARP-1 and LMNA mRNA from PAHs-treated cells and $\beta$-actin mRNA. The $\Delta \mathrm{Ct}_{\text {calibrator }}$ value (mean PARP-1 and LMNA - mean $\beta$ actin) was obtained from the mean Ct value of PARP-1 and LMNA mRNA and $\beta$-actin mRNA from the control cells $(n=10)$. The $\Delta \Delta \mathrm{Ct}$ value was calculated as $\Delta \mathrm{Ct}$ minus $\Delta \mathrm{Ct}_{\text {calibrator }}$. The final relative quantification of PARP-1 and LMNA mRNA was expressed as $\Delta \Delta \mathrm{Ct}$.

2.8. Western Blot. Extracted protein samples (20 $\mu$ g per well) were separated on a $12 \%$ SDS-Bis-Tris polyacrylamide gel. After transfer, the nitrocellulose membrane was incubated over night with $10 \mathrm{~mL}$ of primary antibodies against PARP1, LMNA (Santa Cruz Biotechnology, Delaware Avenue, CA, USA), and $\beta$-actin (Santa Cruz Biotechnology) at $4^{\circ} \mathrm{C}$. The membrane was then incubated with the appropriate goat antimouse IgG antibody (1:1000) (Jackson ImmunoResearch Laboratories, West Grove, PA, USA) to detect biotinylated protein markers in $10 \mathrm{~mL}$ of blocking buffer with gentle agitation for 1 hour at room temperature. The proteins were visualized using a chemiluminescence detection system (Amersham ECL system, London, UK).

2.9. In Vivo Study. For in vivo model study, zebrafish embryos $30 \mathrm{~h}$ after fertilization (hpf) were exposed to $\mathrm{BaP}$ at concentrations of 200, 400,600,800, and $1000 \mathrm{nM}$. Seventy embryos were cultured in $40 \mathrm{~mL}$ of $\mathrm{BaP}$ solution in each petri dish, and there were three replicates for each of the five treatments. Embryos were collected at $54 \mathrm{hpf}, 78 \mathrm{hpf}$, and $102 \mathrm{hpf}$. Embryos were maintained under the same temperature and $\mathrm{pH}$ conditions for the duration of experiments.

\section{Results}

3.1. The Change of Cell Morphology. PAH-untreated h-TERT cells showed compact cellularity with spindle shape. Cells were tightly attached to each other and to the substrate. Generally, direct exposure of PAHs such as BaP, pentacene, fluoranthene, and pyrene depressed the proliferative capacity of h-TERT cells and the cell morphology was altered in each PAH-exposure group. Cells became detached from the subsurface, and cell-to-cell attachments were lost (Figure 1).

3.2. The Change of Total Cell Counts. Depending on the type of PAHs, each cell count showed different aspects. The total number of cells in the THP- 1 and Molt- 4 cell lines decreased 11 days after PAHs exposure. The change in the total number of cells in the THP-1 and Molt- 4 cell lines decreased in 


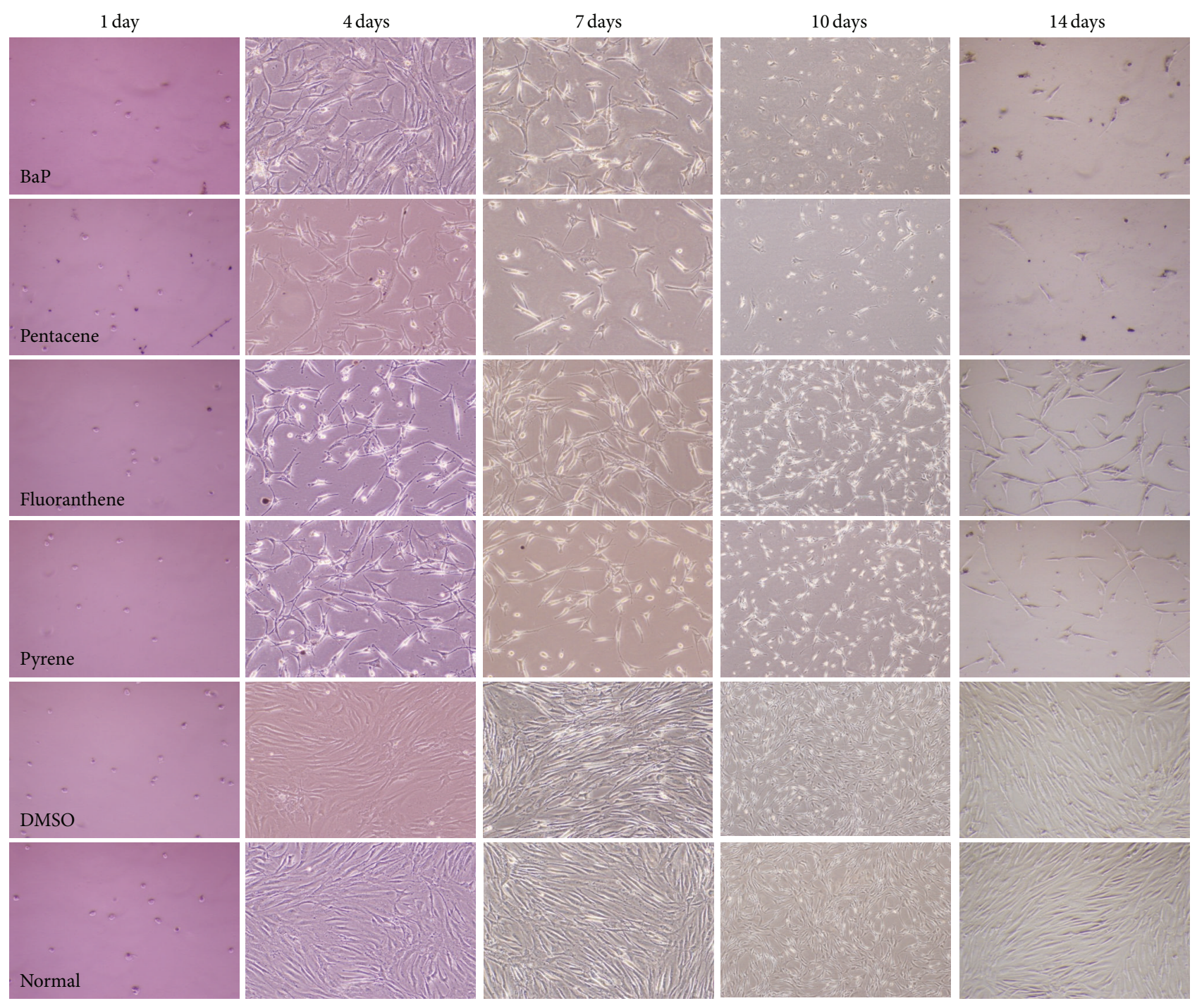

FIGURE 1: Morphological change of human mesenchymal stem (h-TERT) cells after PAHs exposure. PAH-untreated cells (DMSO and normal) showed compact cellularity with spindle shape. h-TERT cells were tightly attached to each other and to the substrate. Generally, direct exposure of PAHs depressed the proliferative capacity of h-TERT cells with a thread-like or round shape and loose cell-to-cell attachment. Each PAHs compound showed different cytotoxic effect. DMSO and normal indicated only DMSO-treatment and culture solution itself (no treatment of PAHs and DMSO), respectively.

a time-dependent manner. In comparison to control group, fluoranthene displayed profound significant reduction in cell count (Figures 2(a) and 2(b)). The change in the total cell count for the THP-1 and Molt-4 cell lines had a similar pattern after PAHs exposure. Cytotoxicity study carried out the experiment with $100 \mu \mathrm{M}$ of PAHs after selecting the minimum concentration that is poisonous to cells.

3.3. Viability and Apoptosis. Viability significantly decreased after two days of exposure to fluoranthene. On the third day of PAHs exposure, viability reduced remarkably in all the cells (Figures 2(c) and 2(d)). Each type of cell lines displayed different proportionality of apoptosis. Several hundreds of PAHs exposure biomarkers were identified in comparison to control group (Supplemental Figure 1).
3.4. Increased mtDNA Copy Number. Mitochondrial contents were increased with different pattern: mtDNA copy number was dramatically elevated after 5-day treatment of fluoranthene and pyrene in both cell line and in vivo zebrafish model. mtDNA copy numbers were generally increased after PAHs exposure in a dose and time-dependent manner in the cell lines. These findings suggested that loss of compensatory ability in response to high levels of oxidative stress was induced by high concentrations of PAHs (Figure 3).

3.5. Sequence Alteration of mtDNA Control Region. Changes of the mtDNA sequence were comprehensively studied by direct sequencing of the mtDNA control region and gene scanning for the determination of mtDNA length and 
THP-1

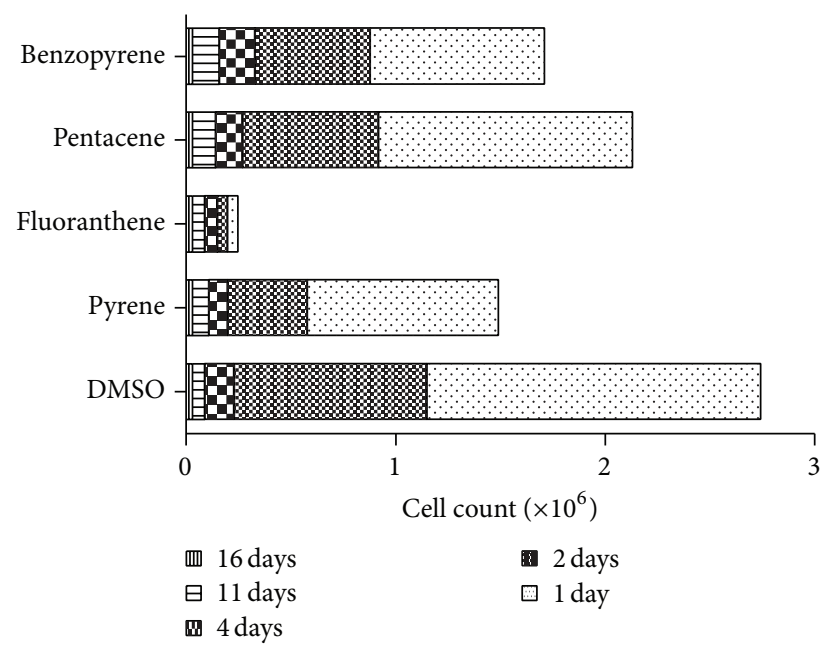

(a)

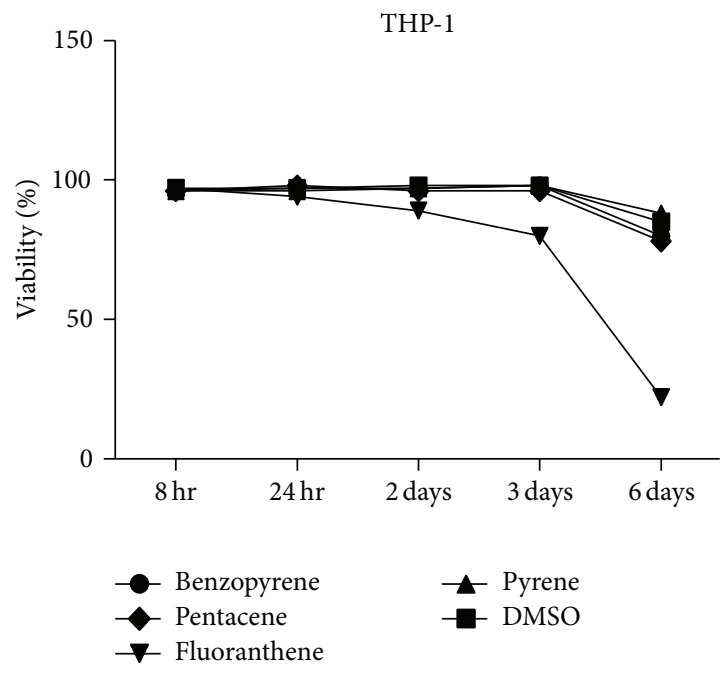

(c)

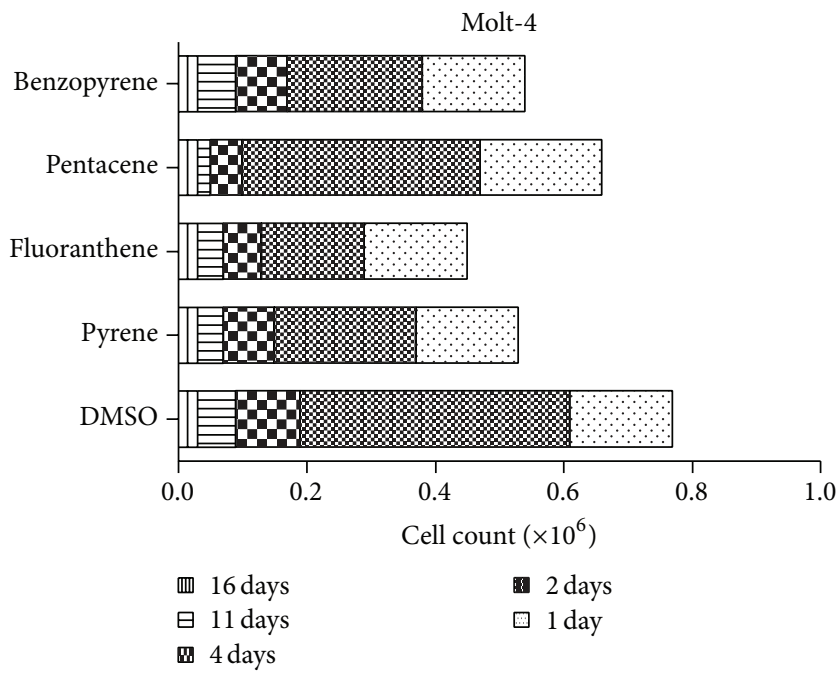

(b)

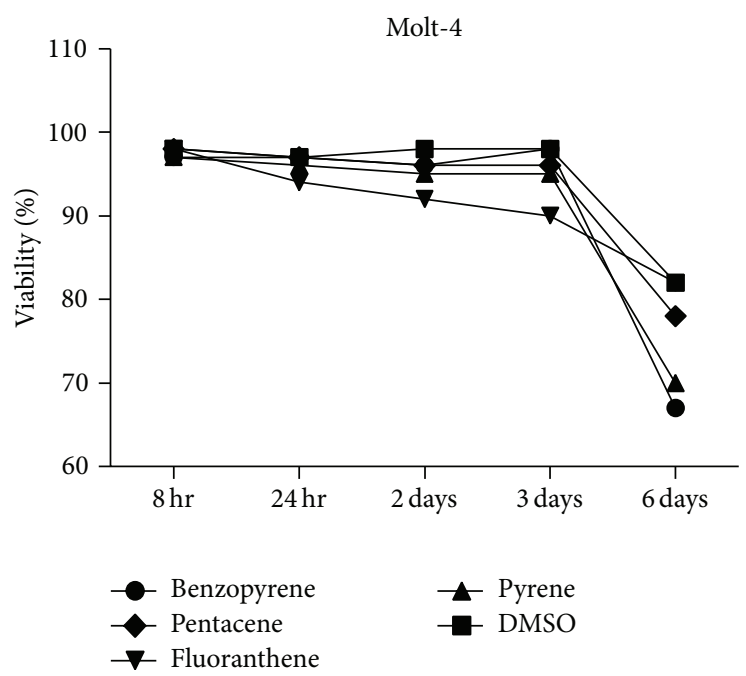

(d)

FIgURE 2: The change of cell count and viability after PAHs exposure in THP-1 and Molt- 4 cell line. Depending on the type of PAHs, each cell count showed different aspects. In comparison to DMSO treated (0.1\%) group, fluoranthene displayed profound significant reduction in cell count, especially in THP-1 and Molt-4 cell line ((a) and (b)). Viability was significantly decreased after fluoranthene exposure for two days. On the third day of PAHs exposure, viability was reduced remarkably in both cell lines ((c) and (d)).

heteroplasmic mutations. No alteration of mtDNA sequences was observed after direct exposure of PAHs during 7 days (Supplemental Figure 2). No alteration of mtDNA minisatellites such as 1618 poly C, 303 poly C and 514 (CA) repeat was found after PAHs exposure.

3.6. Mitochondrial Protein Markers. Several hundreds of cellular proteins in mitochondrial-rich cytoplasmic fraction were profoundly deregulated in comparison to control group (Figure 4). The notable deregulated proteins for PAHs exposure were displayed as follows: LMNA and annexin A1 for BaP; LMNA and DNA topoisomerase 2-alpha for pentacene; PARP-1 for fluoranthene; and talin-1 and DNA topoisomerase 2-alpha for pyrene (Tables 1 and 2).

\subsection{Confirmation of Mitochondrial Protein Markers}

3.7.1. Increased $m R N A$ Expression of PARP-1 and LMNA Gene. mRNA expression of PARP-1 and LMNA gene was generally increased in THP-1 and h-TERT cell lines after exposure of PAHs with different pattern. This finding was confirmed using embryogenesis in zebrafish model (Figure 5).

3.7.2. Increased Protein Expression of PARP-1 and LMNA Gene. The expression of PARP-1 protein was increased after exposure of $\mathrm{BaP}$, pentacene, and fluoranthene. The LMNA proteins were increased after exposure of BaP (Figure 6).

3.8. Morphological Abnormalities of Zebrafish. At $54 \mathrm{hpf}$, embryos treated with $400 \mathrm{nM} \mathrm{BaP}$ exhibited mild pericardial 


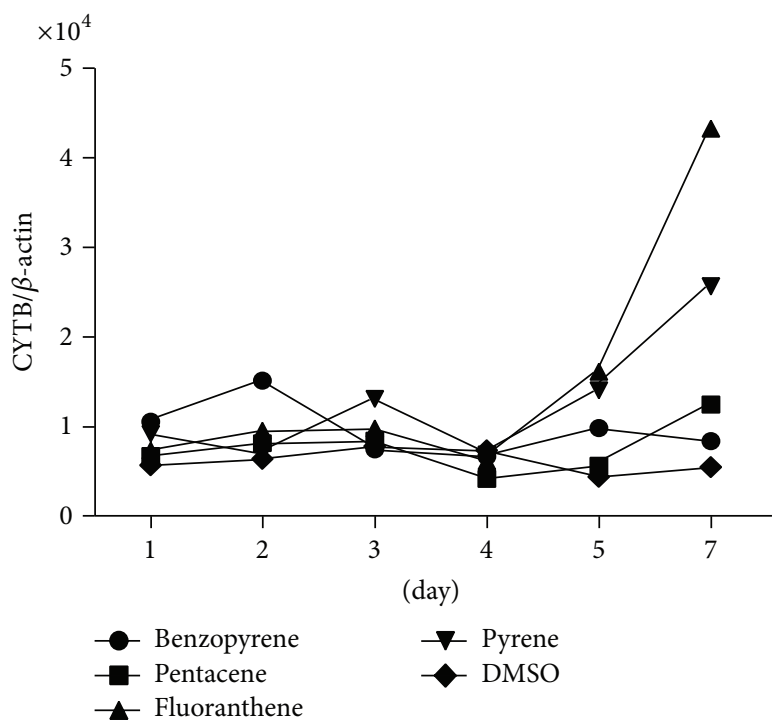

(a)
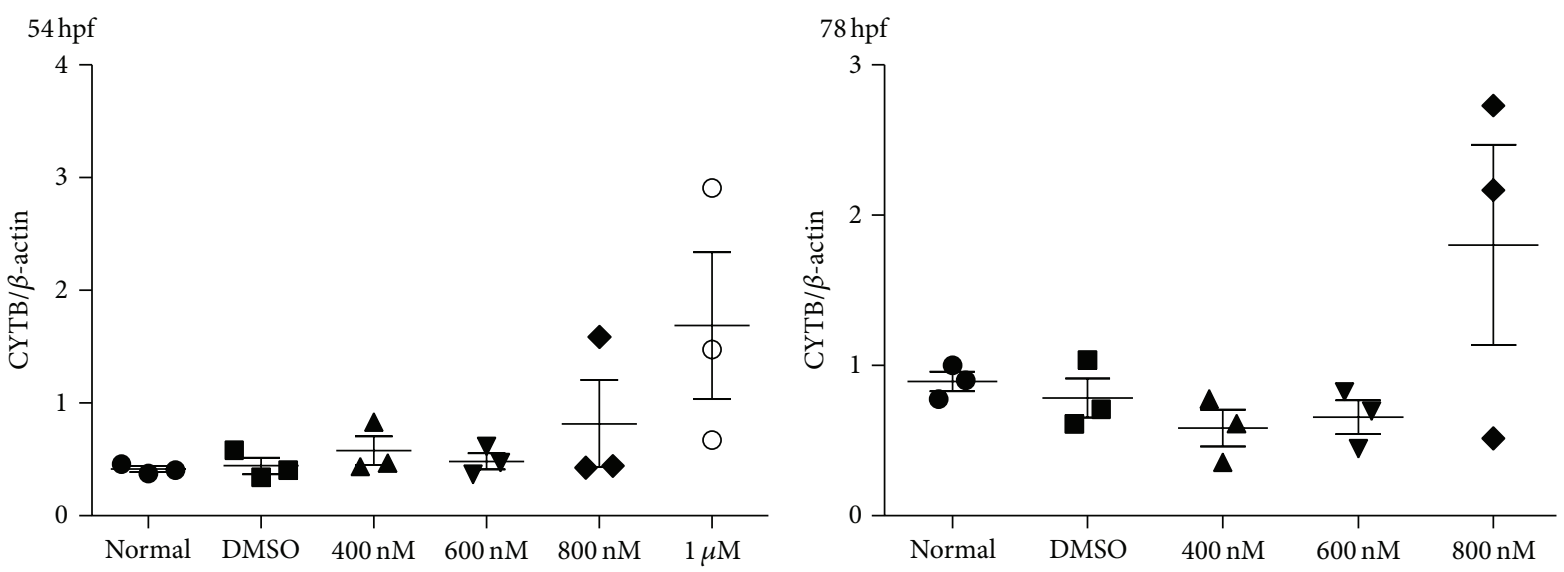

(b)

Figure 3: The change of mtDNA copy number after PAHs exposure. mtDNA copy number was increased after exposure of PAHs with different pattern in THP-1 cell line (a) and in vivo zebrafish model (b). mtDNA copy number was dramatically elevated after 5-day treatment of fluoranthene and pyrene in both THP-1 cell line and in vivo zebrafish model. hpf, hours per fertilization in zebrafish; normal, no treatment group; and DMSO, only DMSO (0.1\%) treated group.

edema and showed dorsal curvature of the body axis (Figure 7). Dorsal curvature was more severe by higher concentration of $\mathrm{BaP}$ as edema accumulated. Notably, eye and jaw growths were similarly reduced by $\mathrm{BaP}$ treatment.

\section{Discussion}

PAHs are known genotoxic agents and induce DNA damaging effects, such as DNA adducts, DNA strand breaks, chromosomal aberrations, sister chromatid exchanges, and micronucleus formation [18]. The main sources of human exposure to PAHs are occupation, passive and active smoking, and food, water, and air pollution [19]. The total intake of carcinogenic PAHs in the general population has been estimated to be $3 \mu \mathrm{g} /$ day [20]. Levels of occupational exposure of $\mathrm{BaP}$, which is one of the main $\mathrm{PAHs}$ compounds, vary widely in different industrial activities and job titles, ranging from 0.1 to $48000 \mathrm{ng} / \mathrm{m}^{3}$ [21-23]. In smokers, BaP levels range from 0.5 to $7.8 \mu \mathrm{g} / 100$ cigarettes when exposure is from mainstream smoke and from 2.5 to $19.9 \mu \mathrm{g} / 100$ cigarettes when it comes from side-stream smoke. Levels from passive smoking are lower, ranging from 0.0028 to $0.76 \mu \mathrm{g} / \mathrm{m}^{3}$ of BaP [24]. Besides occupational exposure, dietary intake seems to be the most important source of PAHs in nonsmokers $[24,25]$. There is a high variation in atmospheric PAHs levels across geographical areas with $\mathrm{BaP}$ concentrations ranging from 0.01 to $100 \mathrm{ng} / \mathrm{m}^{3} \mathrm{BaP}$ [26]. Airborne PAHs are usually analyzed by gas chromatography/mass spectrometry [27, 28] or high performance LC [29-31], mostly from particles collected in a filter after extraction with organic solvents.

In order to exert its deleterious effects, $\mathrm{BaP}$ must be bioactivated. The formation of $\mathrm{BaP}$ o-quinones has been 

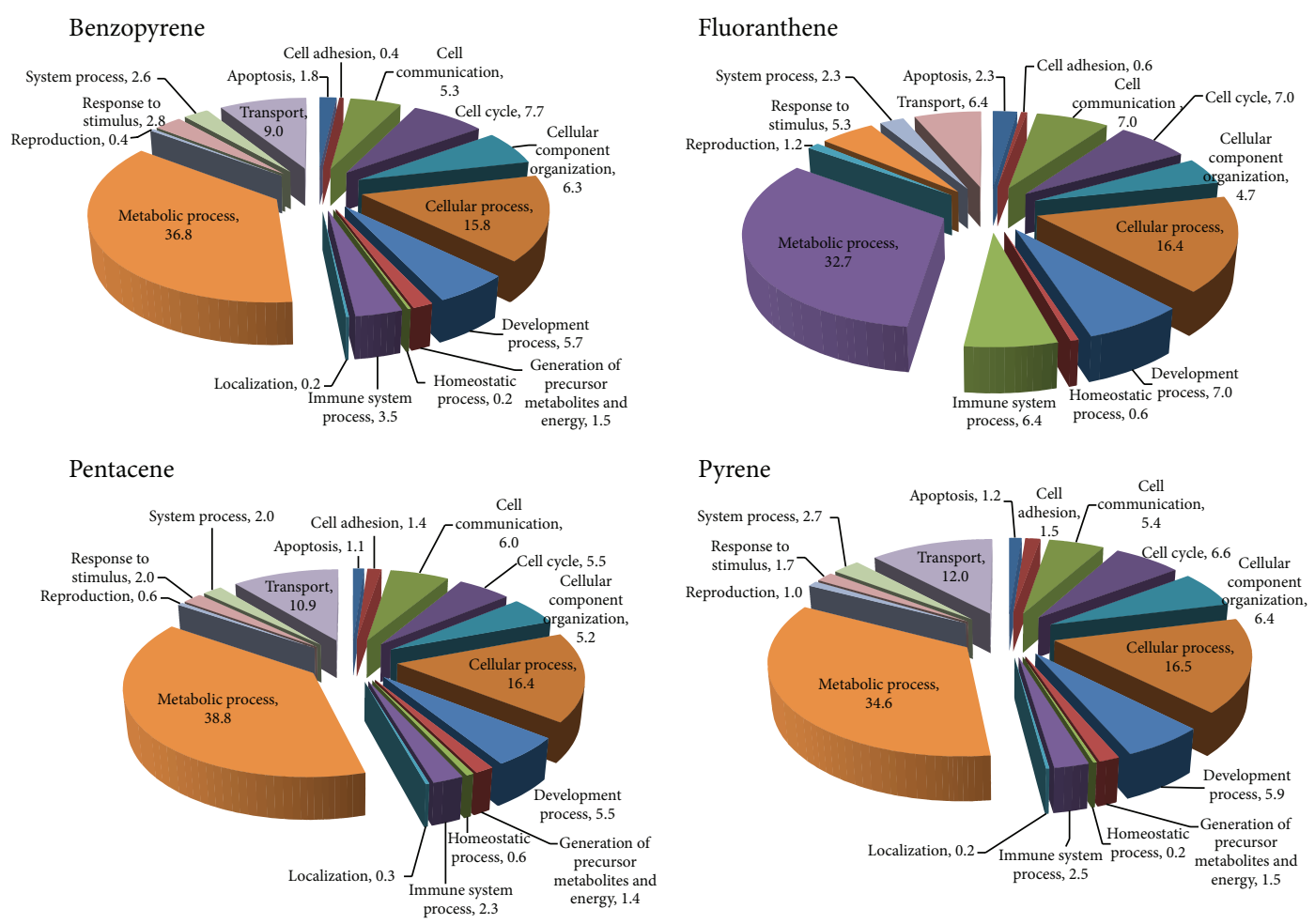

(a)

Benzopyrene

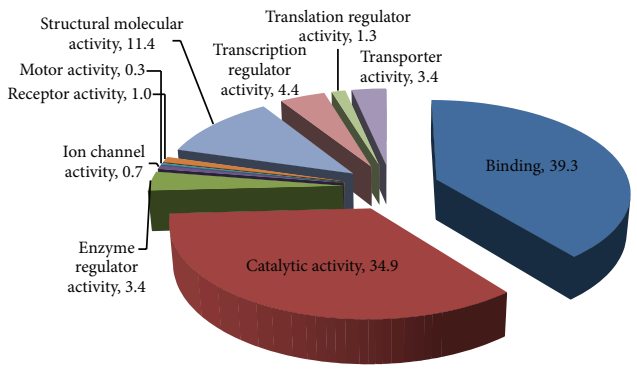

Pentacene

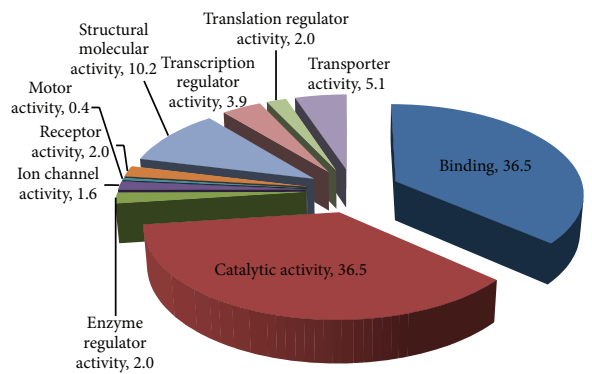

Fluoranthene
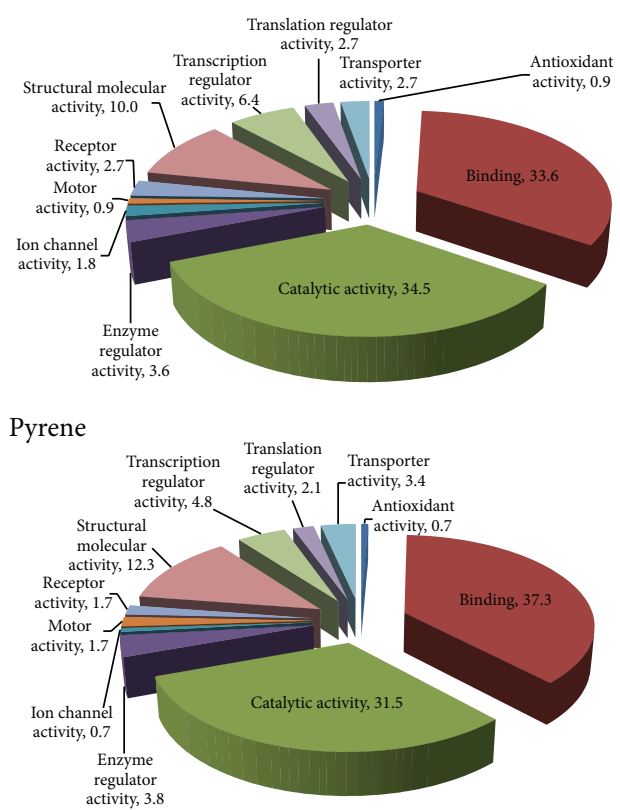

activity, 3.8

(b)

FIGURE 4: Functional grouping of potential candidate biomarkers for PAHs exposure. Identified potential biomarkers were categorized as their biological process (a) and molecular functions (b). These candidate biomarkers for PAHs exposure were isolated using proteomic analysis of mitochondria-rich cellular fraction in THP-1 cell line.

described as one of the $\mathrm{BaP}$ activation pathways. Cytochrome P4501A (CYP1A) is able to produce BaP-7, 8 diol that is further oxidized to BaP-7, 8-dione by AKR1A1 [32]. BaP binds to and activates the aryl hydrocarbon receptor (AhR), being metabolized by the cytochrome P4501A, the microsomal epoxide hydrolase, and the glutathione-S-transferase $\alpha$ [33]. $\mathrm{AhR}$ is a ligand-activated transcription factor involved in the regulation of biological responses to planar aromatic 
TABLE 1: Summary list of identified potential biomarkers for PAHs exposure.

\begin{tabular}{|c|c|c|}
\hline PAHs & Protein & Fold change \\
\hline \multirow{8}{*}{ Benzopyrene } & Vimentin & 19.39 \\
\hline & Annexin A1 & 13.38 \\
\hline & Lamin-A/C & 10.04 \\
\hline & NADPH: adrenodoxin oxidoreductase, mitochondrial isoform 2 precursor & 5.3 \\
\hline & Squalene synthase & 5.3 \\
\hline & Heterogeneous nuclear ribonucleoproteins $\mathrm{A} 2 / \mathrm{B} 1$ isoform $\mathrm{B} 1$ & 4.82 \\
\hline & T-complex protein 1 subunit theta & 4.35 \\
\hline & Talin-1 & 4.35 \\
\hline \multirow{7}{*}{ Pentacene } & Lamin-A/C & 6.9 \\
\hline & DNA topoisomerase 2-alpha & 6.38 \\
\hline & Annexin A1 & 6.38 \\
\hline & Poly[ADP-ribose] polymerase 1 & 5.85 \\
\hline & Squalene synthase & 5.33 \\
\hline & Talin-1 & 5.33 \\
\hline & $\begin{array}{l}\text { PREDICTED: u5 small nuclear ribonucleoprotein } 200 \mathrm{kDa} \text { helicase-like, } \\
\text { partial }\end{array}$ & 4.81 \\
\hline \multirow{6}{*}{ Fluoranthene } & Poly[ADP-ribose] polymerase 1 & 6.21 \\
\hline & Elongation factor 1-gamma & 5.21 \\
\hline & Heat shock $70 \mathrm{kDa}$ protein $1 \mathrm{~A} / 1 \mathrm{~B}$ & 5.21 \\
\hline & Heterogeneous nuclear ribonucleoproteins $\mathrm{A} 2 / \mathrm{B} 1$ isoform $\mathrm{B} 1$ & 5.21 \\
\hline & Probable ATP-dependent RNA helicase DDX5 & 5.21 \\
\hline & T-complex protein 1 subunit theta & 5.21 \\
\hline \multirow{6}{*}{ Pyrene } & Talin-1 & 16.82 \\
\hline & DNA topoisomerase 2-alpha & 8.17 \\
\hline & Filamin- $\mathrm{C}$ isoform $\mathrm{b}$ & 7.16 \\
\hline & E3 SUMO-protein ligase RanBP2 & 5.65 \\
\hline & CAD protein & 5.14 \\
\hline & Poly[ADP-ribose] polymerase 1 & 5.14 \\
\hline
\end{tabular}

TABLE 2: Results of PARP-1 and LMNA protein by repeat proteomic analysis.

\begin{tabular}{lcc}
\hline \multirow{2}{*}{ Protein } & \multicolumn{2}{c}{ Fold change } \\
& First result & Second result \\
\hline PARP-1 (accession no: 156523968) & 3.41 & 3.58 \\
DMSO versus BaP & 5.85 & 4.31 \\
DMSO versus pentacene & 6.21 & 5.34 \\
DMSO versus fluoranthene & 5.14 & 3.41 \\
DMSO versus pyrene & & \\
LMNA (accession no: 27436948) & 10.04 & 4.16 \\
DMSO versus BaP & No change & 0.97 \\
DMSO versus pentacene & 4.50 & 3.00 \\
DMSO versus fluoranthene & 4.14 & 1.80 \\
DMSO versus pyrene &
\end{tabular}

hydrocarbons. AhR ligands have been generally classified into two categories, synthetic or naturally occurring. The first ligands to be discovered were synthetic and members of halogenated aromatic hydrocarbons. Naturally occurring compounds that have been identified as ligands of AhR include derivatives of tryptophan $[34,35]$. The major contributors to air PAHs in the urban and suburban atmosphere are mobile sources from diesel and gasoline engines. Emissions from these sources contain mainly benzo(g,h,i)perylene, pyrene, fluoranthene, and phenanthrene [36], so that measuring only $\mathrm{BaP}$ as an index substance may result in exposure underestimation [3].

In this study, a broad molecular investigation of the mitochondrial genome and proteome after PAHs exposure showed an increased mtDNA copy number, PARP-1, and LMNA protein, which could be used as biomarkers for exposure of PAHs in cell lines. PAHs directly might cause an increase in the generation of intracellular ROS, subsequently resulting in a change of the mtDNA content, and proteome. The oxidative stress induced by PAHs can lead to an increase 

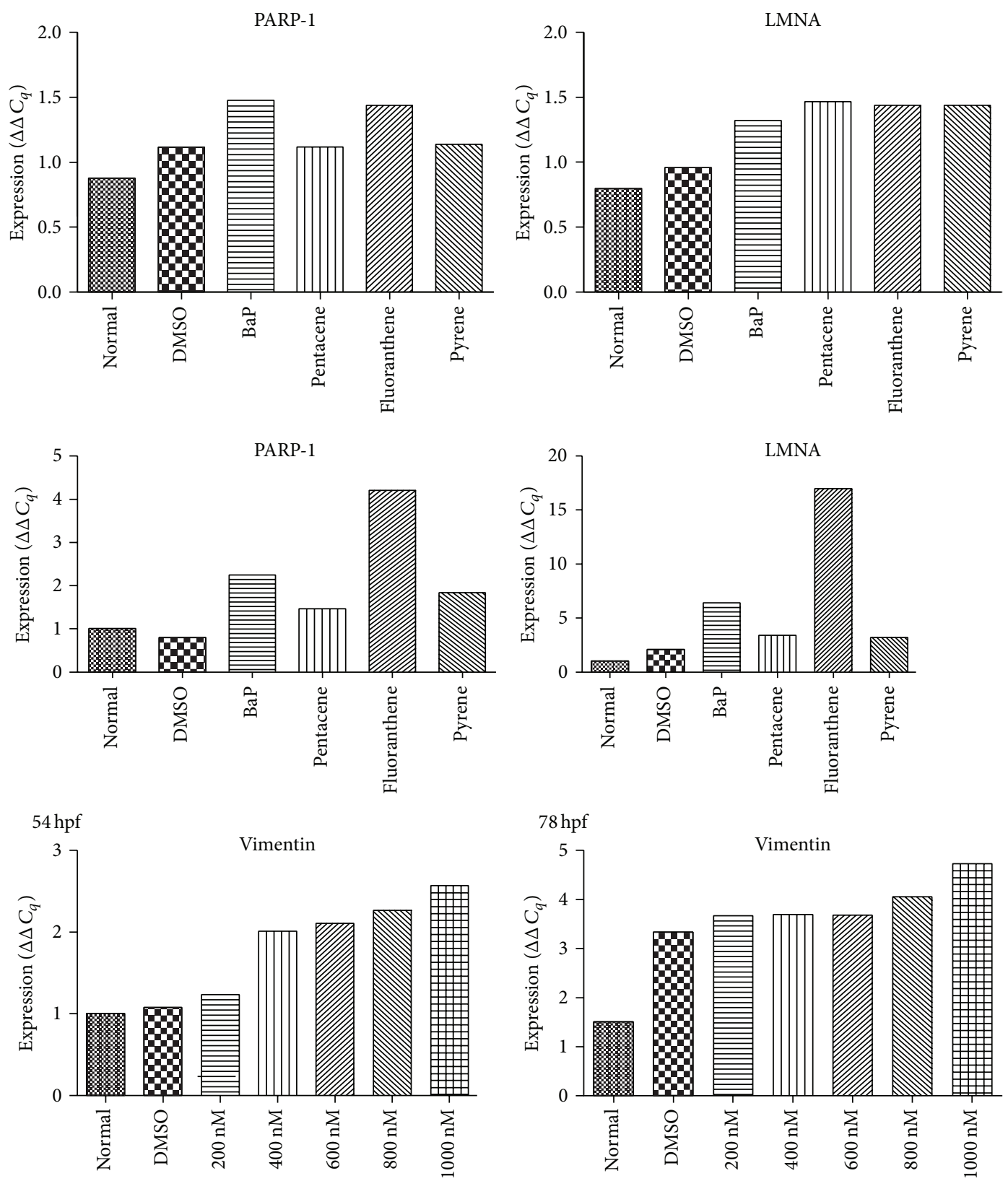

FIGURE 5: mRNA expression study of candidate biomarker genes. mRNA expression of PARP-1 and LMNA gene was generally increased in THP-1 and h-TERT cell lines after exposure of PAHs with different pattern. Normal, no treatment group; DMSO, only DMSO (0.1\%) treated group.

in mitochondrial mass and mitochondrial membrane potential. The mitochondrial genome is highly susceptible to DNA damage caused by ROS and mutagens and has higher rates of mutation than does the nuclear genome. In addition, DNA damage persists longer in the mitochondrial genome. The absence of histones that provide packaging and protection of nuclear DNA and the error-prone replication and repair of mitochondrial genes all contribute to the vulnerable nature of mitochondrial DNA [37]. Therefore, the present study targeted the mitochondrial genome and proteome to identify biomarkers associated with PAH exposure. The results of the present study showed that, after PAHs exposure, mtDNA copy number was increased. The increase of mtDNA copy number was thought to compensate for declining respiratory function during the oxidative stress after PAH exposure.

Mitochondria-rich cellular proteome was then studied to determine whether biomarkers associated with exposure of PAHs could be identified. The result showed that PARP1 and LMNA protein might be a novel universal biomarker associated with exposure of PAHs. PARP is a monomeric protease widely present in the nuclei of most eukaryotic cells that is associated with the occurrence and development of a variety of diseases. PARP-1, the best characterized member of the PARP family, which currently comprises 18 members, is 


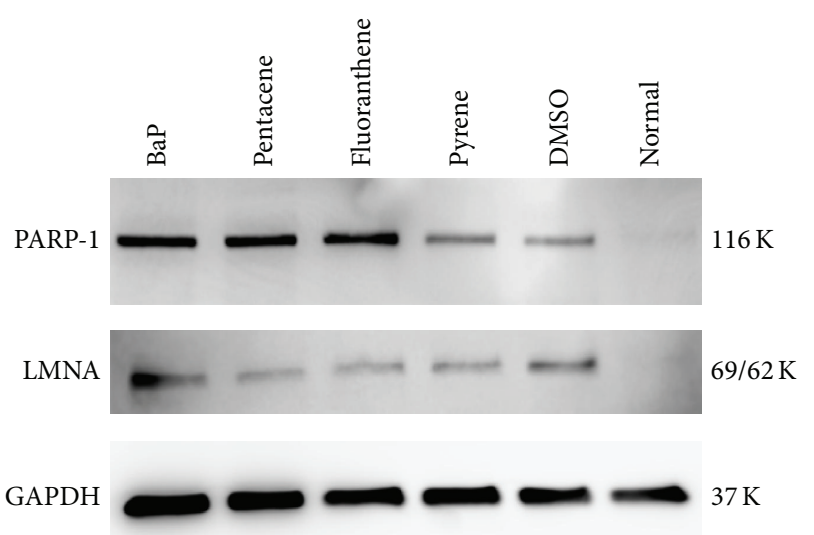

FIgURE 6: Confirmation of PARP-1 and LMNA biomarkers using Western blot. The expression of PARP-1 was remarkably increased after exposure of BaP, pentacene, and fluoranthene (100 $\mu \mathrm{M}$ concentration). LMNA protein was highly expressed after BaP exposure. Normal, no treatment group; DMSO, only DMSO (0.1\%) treated group; K, kilodalton.

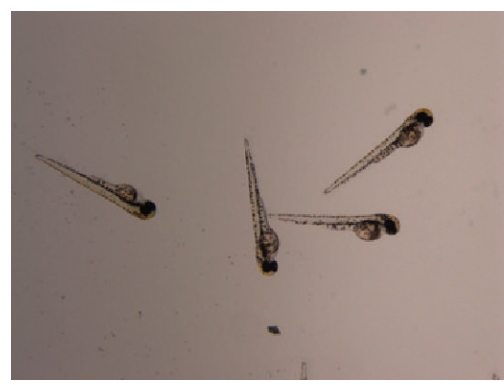

Normal

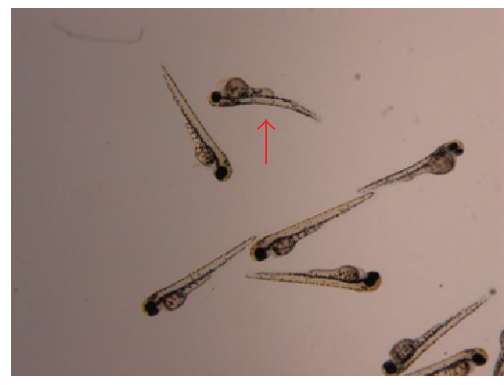

$400 \mathrm{nM}$

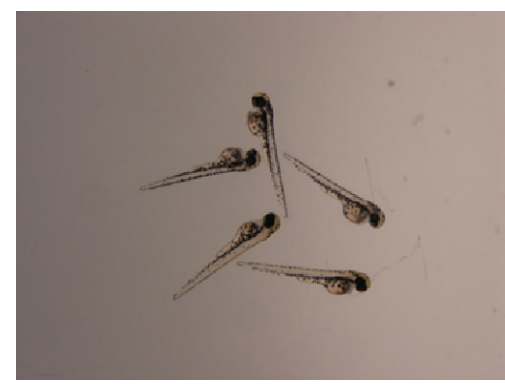

DMSO

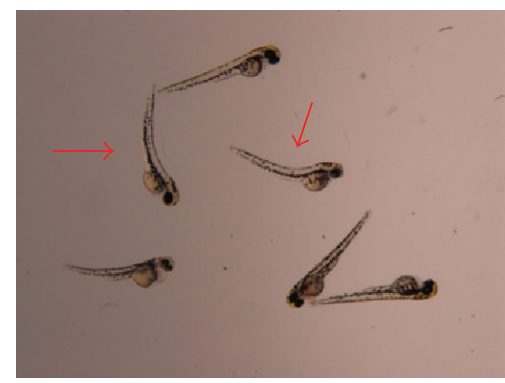

$600 \mathrm{nM}$

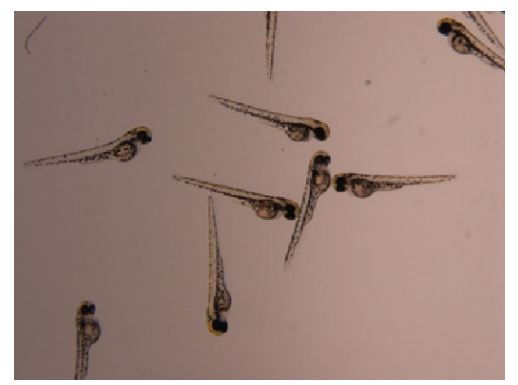

$200 \mathrm{nM}$

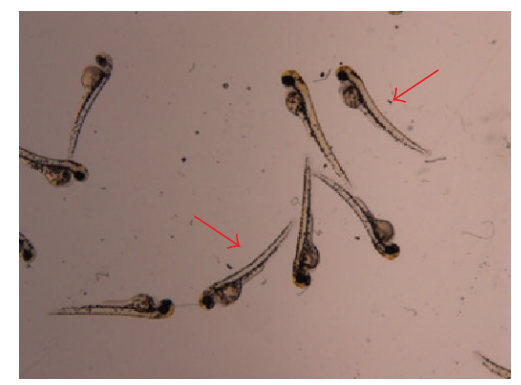

$800 \mathrm{nM}$

FIGURE 7: Morphological abnormalities in the general shape of zebrafish after BaP exposure. Obvious morphological abnormalities including curved backbone (arrow) were developed after exposure of more than $400 \mathrm{nM}$ concentration of BaP during the embryogenesis (54 hours per fertilization).

an abundant nuclear enzyme implicated in cellular responses to DNA injury provoked by genotoxic stress. PARP is involved in DNA repair and transcriptional regulation and is now recognized as a key regulator of cell survival and cell death as well as a master component of a number of transcription factors involved in tumor development and inflammation. PARP becomes activated in response to oxidative DNA damage and depletes cellular energy pools, thus leading to cellular dysfunction in various tissues. The activation of PARP may also induce various cell death processes and promotes an inflammatory response associated with multiple organ failure [38]. It is known to activate nuclear factor $-\kappa \mathrm{B}(\mathrm{NF}-\kappa \mathrm{B})$ through a variety of pathways, which can lead to increased expression of NF- $\kappa \mathrm{B}$-dependent genes such as oncogenes, cell adhesion molecules, matrix metalloproteinases, and growth factors [39]. Inhibition of PARP activity is protective in a wide range of inflammatory and ischemia-reperfusion-associated diseases, including cardiovascular diseases, diabetes, rheumatoid arthritis, endotoxic shock, and stroke [38]. LMNA, nuclear intermediate filament proteins, is a basic component of the nuclear lamina. Mutations in LMNA are associated with a broad range of laminopathies, congenital diseases affecting tissue regeneration, and homeostasis. This study showed global profiling of toxic changes of PAHs in cell lines, h-TERT, and zebrafish model. The change of mitochondrial genome (increased 
mtDNA copy number and mass) was closely associated with PAHs exposure in hematopoietic and mesenchymal stem cells. Among cellular proteins, LMNA, talin-1, and annexin A1 were remarkably elevated after exposure of PAHs; these may play a role as biomarkers for PAHs exposure. In zebrafish embryos, we observed pericardial edema and dorsal curvature of the body axis associated with BaP. Zebrafish, specifically embryo stage, showed suitable in vivo model for monitoring $\mathrm{BaP}$ exposure to hematopoietic tissue and other organs.

\section{Conclusions}

Direct exposure to PAHs induced alteration of the mitochondrial genome including increased mtDNA copy number. The proteomic analysis of the mitochondria-rich cellular fraction showed that PARP-1 and LMNA were a novel universal biomarker associated with exposure of PAHs. Thus mtDNA copy number, PARP-1, and LMNA protein might be useful biomarkers associated with PAHs toxicity and hematotoxicity.

\section{Conflict of Interests}

The authors declare that there is no conflict of interests regarding the publication of this paper.

\section{Acknowledgments}

The authors are thankful to the National Research Foundation of Korea (NRF) and grants funded by the Korea government (MEST) (no. 2011-0015304); the Leading Foreign Research Institute Recruitment Program through the National Research Foundation of Korea (NRF) funded by the Ministry of Education, Science and Technology (MEST) (no. 2011-0030034); and a grant from the National R\&D Program for Cancer Control, Ministry of Health \& Welfare, Republic of Korea (no. 2013-1320070).

\section{References}

[1] S. S. Raychoudhury and D. Kubinski, "Polycyclic aromatic hydrocarbon-induced cytotoxicity in cultured rat Sertoli cells involves differential apoptotic response," Environmental Health Perspectives, vol. 111, no. 1, pp. 33-38, 2003.

[2] D. H. Phillips, "Fifty years of benzo(a)pyrene," Nature, vol. 303, no. 5917 , pp. $468-472,1983$.

[3] G. Castaño-Vinyals, A. D’Errico, N. Malats, and M. Kogevinas, "Biomarkers of exposure to polycyclic aromatic hydrocarbons from environmental air pollution," Occupational and Environmental Medicine, vol. 61, no. 4, article e12, 2004.

[4] S. Brzeźnicki, M. Jakubowski, and B. Czerski, "Elimination of 1-hydroxypyrene after human volunteer exposure to polycyclic aromatic hydrocarbons," International Archives of Occupational and Environmental Health, vol. 70, no. 4, pp. 257-260, 1997.

[5] F. J. Jongeneelen and R. P. Bos, "Excretion of pyrene and hydroxypyrene in urine," Cancer Letters, vol. 51, no. 2, pp. 175$177,1990$.
[6] T. J. Buckley and P. J. Lioy, "An examination of the time course from human dietary exposure to polycyclic aromatic hydrocarbons to urinary elimination of 1-hydroxypyrene," British Journal of Industrial Medicine, vol. 49, no. 2, pp. 113-124, 1992.

[7] F. J. van Schooten, F. J. Jongeneelen, M. J. Hillebrand et al., "Polycyclic aromatic hydrocarbon-DNA adducts in white blood cell DNA and 1-hydroxypyrene in the urine from aluminum workers: relation with job category and synergistic effect of smoking," Cancer Epidemiology Biomarkers \& Prevention, vol. 4, no. 1, pp. 69-77, 1995.

[8] J. Jacob, G. Grimmer, G. Raab, and A. Schmoldt, “The metabolism of pyrene by rat liver microsomes and the influence of various mono-oxygenase inducers," Xenobiotica, vol. 12, no. 1, pp. 45-53, 1982.

[9] J. D. Butler and P. Crossley, "An appraisal of relative airborne sub-urban concentrations of polycyclic aromatic hydrocarbons monitored indoors and outdoors," Science of the Total Environment, vol. 11, no. 1, pp. 53-58, 1979.

[10] F. J. Jongeneelen, R. B. M. Anzion, and P. T. Henderson, "Determination of hydroxylated metabolites of polycyclic aromatic hydrocarbons in urine," Journal of Chromatography B: Biomedical Sciences and Applications, vol. 413, no. C, pp. 227-232, 1987.

[11] M. Bouchard, L. Pinsonneault, C. Tremblay, and J. Weber, "Biological monitoring of environmental exposure to polycyclic aromatic hydrocarbons in subjects living in the vicinity of a creosote impregnation plant," International Archives of Occupational and Environmental Health, vol. 74, no. 7, pp. 505-513, 2001.

[12] J. N. Meyer, M. C. K. Leung, J. P. Rooney et al., "Mitochondria as a target of environmental toxicants," Toxicological Sciences, vol. 134, no. 1, pp. 1-17, 2013.

[13] H. Eom, H. Kim, D. Han et al., "Mitochondrial DNA copy number and hnRNP A2/B1 protein: biomarkers for direct exposure of benzene," Environmental Toxicology and Chemistry, vol. 30, no. 12, pp. 2762-2770, 2011.

[14] P. Haffter, M. Granato, M. Brand et al., "The identification of genes with unique and essential functions in the development of the zebrafish, Danio rerio," Development, vol. 123, pp. 1-36, 1996.

[15] R. T. Peterson, B. A. Link, J. E. Dowling, and S. L. Schreiber, "Small molecule developmental screens reveal the logic and timing of vertebrate development," Proceedings of the National Academy of Sciences of the United States of America, vol. 97, no. 24, pp. 12965-12969, 2000.

[16] R. T. Peterson, J. D. Mably, J. N. Chen, and M. C. Fishman, "Convergence of distinct pathways to heart patterning revealed by the small molecule concentramide and the mutation heartand-soul," Current Biology, vol. 11, no. 19, pp. 1481-1491, 2001.

[17] M. Gnecchi and L. G. Melo, "Bone marrow-derived mesenchymal stem cells: isolation, expansion, characterization, viral transduction, and production of conditioned medium," Methods in Molecular Biology, vol. 482, pp. 281-294, 2009.

[18] S. S. Franco, A. C. Nardocci, and W. M. R. Günther, "PAH biomarkers for human health risk assessment: a review of the state-of-the-art," Cadernos de Saude Publica, vol. 24, no. 4, pp. S569-S580, 2008.

[19] F. J. Jongeneelen, "Methods for routine biological monitoring of carcinogenic PAH-mixtures," Science of the Total Environment, vol. 199, no. 1-2, pp. 141-149, 1997.

[20] M. M. Mumtaz, J. D. George, K. W. Gold, W. Cibulas, and C. T. Derosa, "ATSDR evaluation of health effects of chemicals. 
IV. Polycyclic aromatic hydrocarbons (PAHs): understanding a complex problem," Toxicology and Industrial Health, vol. 12, no. 6, pp. 742-995, 1996.

[21] J. Angerer, C. Mannschreck, and J. Gündel, "Biological monitoring and biochemical effect monitoring of exposure to polycyclic aromatic hydrocarbons," International Archives of Occupational and Environmental Health, vol. 70, no. 6, pp. 365-377, 1997.

[22] S. Ovrebo, P. E. Fjeldstad, E. Grzybowska, E. H. Kura, M. Chorazy, and A. Haugen, "Biological monitoring of polycyclic aromatic hydrocarbon exposure in a highly polluted area of Poland," Environmental Health Perspectives, vol. 103, no. 9, pp. 838-843, 1995.

[23] Z. H. Zhao, W. Y. Quan, and D. H. Tian, "Urinary 1-hydroxypyrene as an indicator of human exposure to ambient polycyclic aromatic hydrocarbons in a coal-burning environment," Science of the Total Environment, vol. 92, pp. 145-154, 1990.

[24] "Polynuclear aromatic compounds-part 1: chemical, environmental and experimental data," IARC Monographs on the Evaluation of Carcinogenic Risks to Humans, vol. 32, pp. 1-453, 1983.

[25] G. Scherer, S. Frank, K. Riedel, I. Meger-Kossien, and T. Renner, "Biomonitoring of exposure to polycyclic aromatic hydrocarbons of nonoccupationally exposed persons," Cancer Epidemiology Biomarkers and Prevention, vol. 9, no. 4, pp. 373-380, 2000.

[26] A. Vyskocil, Z. Fiala, D. Fialova, V. Krajak, and C. Viau, "Environmental exposure to polycyclic aromatic hydrocarbons in Czech Republic," Human and Experimental Toxicology, vol. 16, no. 10, pp. 589-595, 1997.

[27] J. L. Mumford, X. Lee, J. Lewtas, T. L. Young, and R. M. Santella, "DNA adducts as biomarkers for assessing exposure to polycyclic aromatic hydrocarbons in tissues from Xuan Wei women with high exposure to coal combustion emissions and high lung cancer mortality," Environmental Health Perspectives, vol. 99, pp. 83-87, 1993.

[28] M. C. Poirier, A. Weston, B. Schoket et al., "Biomonitoring of United States Army soldiers serving in Kuwait in 1991," Cancer Epidemiology Biomarkers and Prevention, vol. 7, no. 6, pp. 545551, 1998.

[29] D. H. Kang, N. Rothman, M. C. Poirier et al., "Interindividual differences in the concentration of 1-hydroxypyreneglucuronide in urine and polycyclic aromatic hydrocarbonDNA adducts in peripheral white blood cells after charbroiled beef consumption," Carcinogenesis, vol. 16, no. 5, pp. 1079-1085, 1995.

[30] J. Lewtas, D. Walsh, R. Williams, and L. Dobiášs, "Air pollution exposure-DNA adduct dosimetry in humans and rodents: Evidence for non-linearity at high doses," Mutation Research, vol. 378 , no. 1-2, pp. 51-63, 1997.

[31] M. Peluso, F. Merlo, A. Munnia et al., "32P-postlabeling detection of aromatic adducts in the white blood cell DNA of nonsmoking police officers," Cancer Epidemiology Biomarkers and Prevention, vol. 7, no. 1, pp. 3-11, 1998.

[32] N. T. Palackal, M. E. Burczynski, R. G. Harvey, and T. M. Penning, "The ubiquitous aldehyde reductase (AKR1A1) oxidizes proximate carcinogen trans-dihydrodiols to o-quinones: potential role in polycyclic aromatic hydrocarbon activation," Biochemistry, vol. 40, no. 36, pp. 10901-10910, 2001.

[33] S. M. Heidel, P. S. MacWilliams, W. M. Baird et al., "Cytochrome P4501B1 mediates induction of bone marrow cytotoxicity and preleukemia cells in mice treated with 7,12dimethylbenz[a]anthracene," Cancer Research, vol. 60, no. 13, pp. 3454-3460, 2000.
[34] M. S. Denison and S. R. Nagy, "Activation of the aryl hydrocarbon receptor by structurally diverse exogenous and endogenous chemicals," Annual Review of Pharmacology and Toxicology, vol. 43, pp. 309-334, 2003.

[35] P. E. Douben, PAHs: An Ecotoxicological Perspective, Wiley \& Sons, 2003.

[36] J. Santodonato, P. Howard, and D. Basu, "Health and ecological assessment of polynuclear aromatic hydrocarbons," Journal of Environmental Pathology and Toxicology, vol. 5, no. 1, pp. 1-364, 1981.

[37] B. G. Masayesva, E. Mambo, R. J. Taylor et al., "Mitochondrial DNA content increase in response to cigarette smoking," Cancer Epidemiology Biomarkers and Prevention, vol. 15, no. 1, pp. 1924, 2006.

[38] A. Peralta-Leal, J. M. Rodríguez-Vargas, R. Aguilar-Quesada et al., "PARP inhibitors: new partners in the therapy of cancer and inflammatory diseases," Free Radical Biology and Medicine, vol. 47, no. 1, pp. 13-26, 2009.

[39] P. O. Hassa, C. Buerki, C. Lombardi, R. Imhof, and M. O. Hottiger, "Transcriptional coactivation of nuclear Factor- $\kappa \mathrm{B}$ dependent gene expression by $\mathrm{p} 300$ is regulated by poly(ADP)ribose polymerase-1," Journal of Biological Chemistry, vol. 278, no. 46, pp. 45145-45153, 2003. 

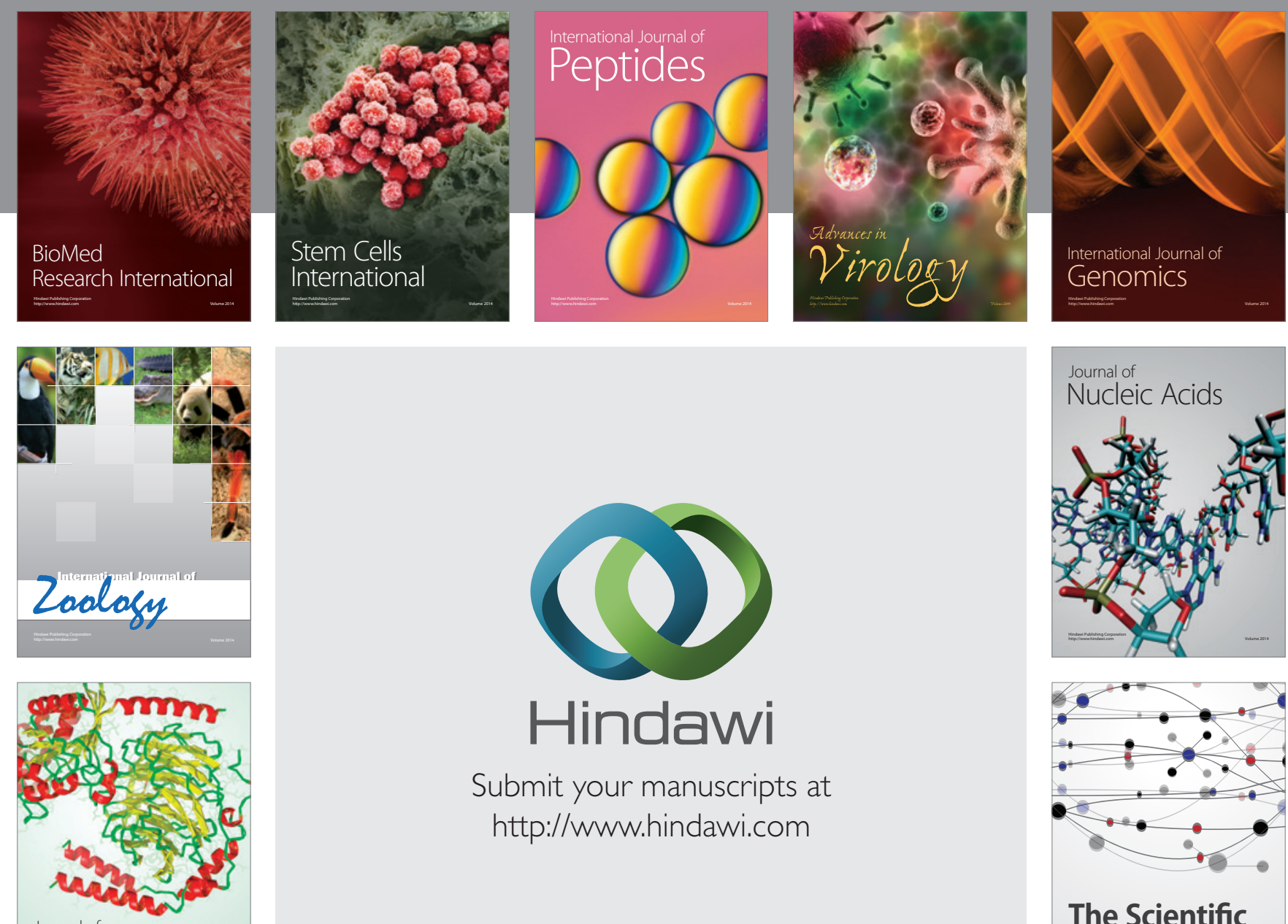

Submit your manuscripts at

http://www.hindawi.com

Journal of
Signal Transduction
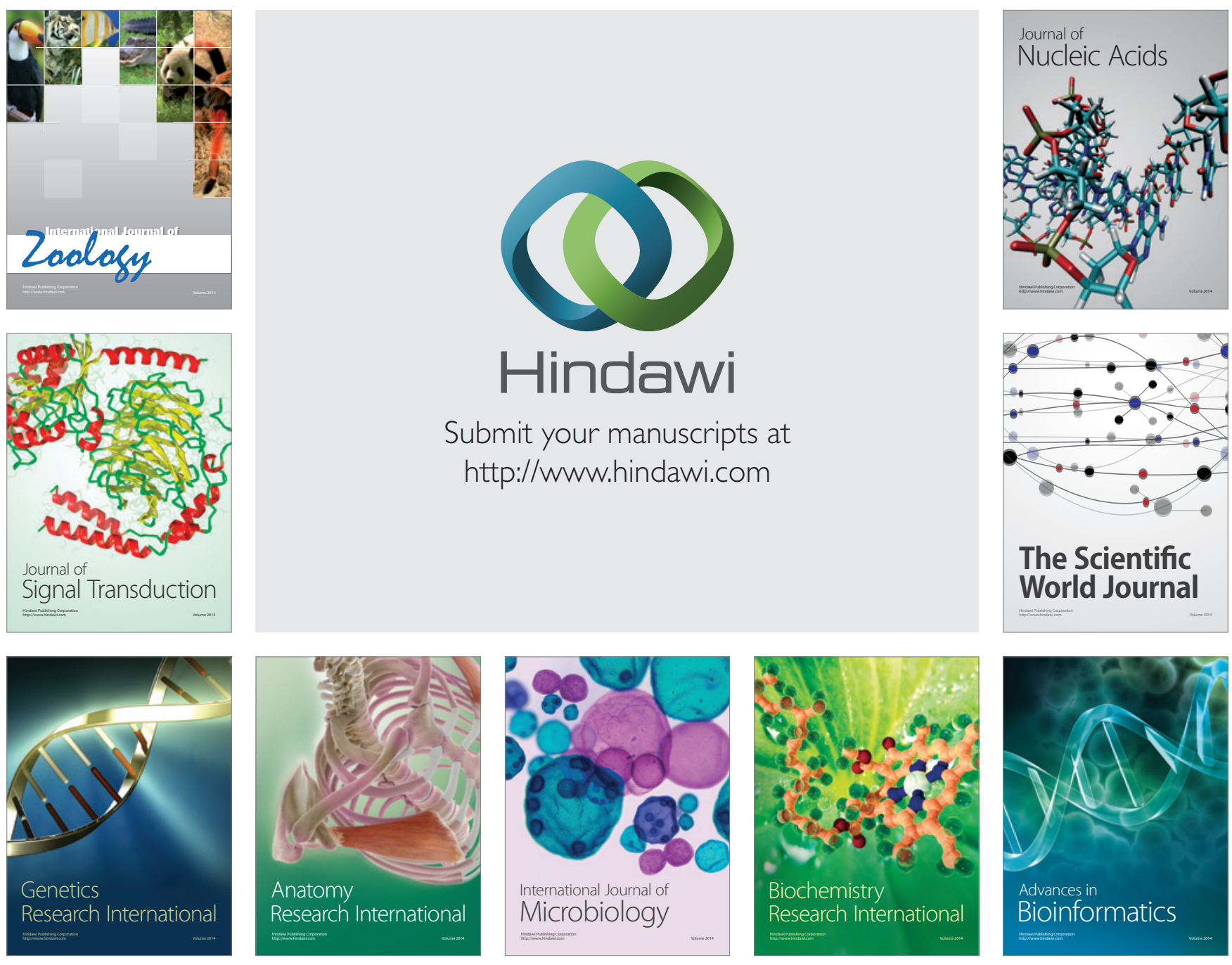

The Scientific World Journal
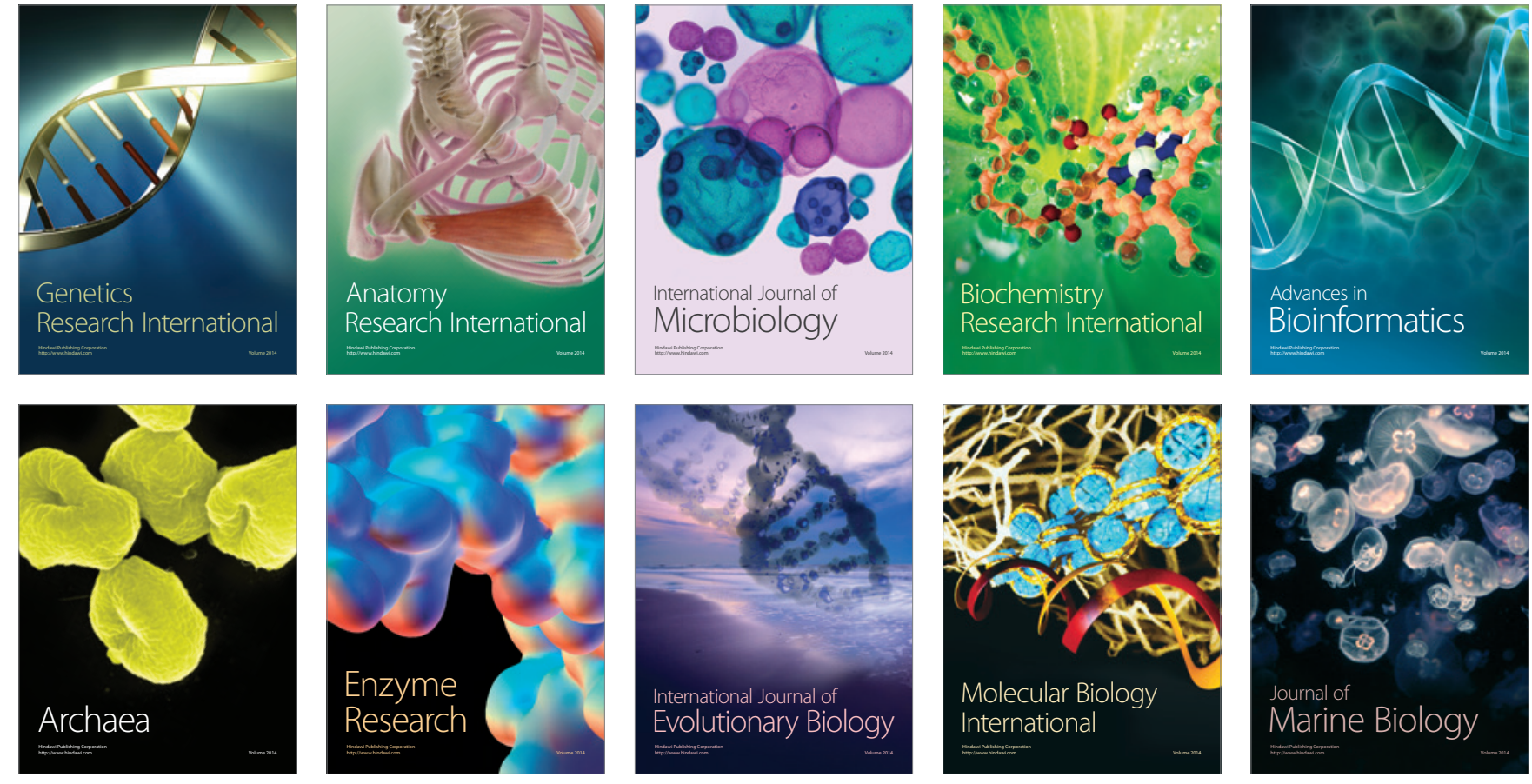